\title{
Personal And Professional Characteristics Of A Good Muslim Doctor: Perception Of Newly Graduated Doctors
}

\author{
Azmi AN ${ }^{a}$, Jamilah Ja, Dzulkhairi $M R^{a}$, Ramli $S^{a}$, Ariff $O^{b}$, Nasri Ismail $N M^{a}$ \\ ${ }^{a}$ Faculty of Medicine and Health Sciences, Universiti Sains Islam Malaysia, Jalan Pandan Utama Pandan \\ Indah, 55100 Kuala Lumpur. \\ ${ }^{b}$ Kulliyyah of Medicine, International Islamic University Malaysia, Indera Mahkota, Kuantan, Pahang.
}

\begin{abstract}
Introduction: The Medical Faculty of Universiti Sains Islam Malaysia (USIM) aims to produce good Muslim doctors (GMD) who are able to practise medicine that is integrated with Islamic values. Islamic courses and Medical Ethics are integrated into the curriculum in its effort to provide adequate Islamic knowledge and nurturing professionalism as a process of personal and professional development (PPD) within the framework of Islamic teaching. The objective of the study was to evaluate the perception of graduates and students of characteristics of a GMD. Method: A self-administered questionnaire was distributed to the participants. The respondents were asked to rate their level of agreement or disagreement on the statements that represent the characteristics of a GMD. Statistical analysis of the data was carried out using SPSS version 18.0. The mean, median and inter quartile ranges of the characteristics were determined and differences between the groups were analysed using Mann-Whitney $U$ test. Results: Results showed significant difference between gender for the item "Conscious of professional ethics" $(p=0.021)$. Significant differences were seen in the median scores between the graduates and the final year students in four out of six items for personal characteristic. Conclusion: Islamic input in the medical curriculum and the teaching of professionalism has an impact on graduate perception of characteristics of a GMD. Further improvement in the teaching of professionalism among undergraduates is necessary in order to promote greater impact on the understanding and internalization of characteristics of a GMD. The Islamic input in the medical curriculum can thus be regarded as the blueprint for PPD of medical undergraduates to become a GMD.
\end{abstract}

Keywords: Islamic input, medical curriculum, professionalism, graduates, students, USIM

\section{INTRODUCTION}

Islamic Law (shari'ah) governs all aspects of a Muslim's life, whether in conducting professional or carrying out daily activities. A Muslim doctor is mindful that he/she is first a Muslim and then a doctor. As a Muslim, one faithfully observes one's relationship with Allah, other fellow human being and the environment. As a good Muslim doctor, one is committed to medical professionalism and good values such as faith, God-consciousness, best character, excellent performance, strife towards perfection, responsibility and self-accountability which is regarded as a form of worship (i'badah) that earns reward from Allah. ${ }^{1}$

Corresponding author:

Dr. Ahmad Najib Azmi

Faculty of Medicine and Health Sciences,

Universiti Sains Islam Malaysia,

Jalan Pandan Utama,

Pandan Indah, 55100 Kuala Lumpur.

Tel: $+603-42892473$

Fax: +603-42892447

Email address: najibaz@usim.edu.my
The medical curriculum of the Faculty of Medicine and Health Sciences of Universiti Sains Islam Malaysia (USIM) aims to produce good Muslim doctors who are able to practice medicine that is integrated with Islamic values. It is envisaged that Islamic courses that are integrated into the curriculum throughout the 6-year programme, provide adequate Islamic knowledge in the effort to inculcate professionalism that is in consonance with Islam. Islamic, moral and ethical values are incorporated in all teaching-learning activities in both preclinical and clinical phases, including the personal and professional development workshops and community engagement. The Islamic courses which are incorporated in the medical curriculum are courses related to the history of medicine, science and medicine revealed in the al Quran and practised by the Prophet, Islamic behaviour, Islamic ethics and understanding medicine in light of Islamic jurisprudence. Medical professionalism is being introduced in the behavioural science course and in basic clinical and communication skills in the preclinical year. The course on Islamic behaviour emphasises on methods of cleansing the heart and 
replacing wrong-doings with good deeds, at the end of which is to produce God-fearing and God-concious individuals. ${ }^{2}$ The actual teaching of medical ethics begins at the beginning of the clinical year and is emphasised during bedside teachings and interactions with patients in the wards and clinics. In addition, students have the opportunity to demonstrate professionalism during interactions with the community in selected villages, during health interventions conducted following community health surveys, health activities as well as with the public attending the nearby mosque. The course in Islamic jurisprudence exposes the students to the application of methodology of derivation of Law (shari'ah) into medical practice. At the end of the final year, a two-week course on Islamic medical ethics is conducted by means of participation of students in seminars, debates and role play on common clinical scenarios where doctors have to make ethical decisions. Hopefully, at the end of the undergraduate training, students would be able to internalise the Islamic values in their personal and professional development that make them good Muslim doctors. Thus, the objective of the study was to evaluate the perception of the graduates and students on the personal and professional characteristics of a good Muslim doctor as desired by the curriculum.

\section{METHODOLOGY}

A cross-sectional study was conducted on 75 newly graduated doctors of USIM and 43 final year medical students. The medical doctors were the first cohort (2010/2011) and second cohort (2011/2012) of graduates serving the Malaysian Ministry of Health hospitals throughout Malaysia in various medical dsiciplines. The final year medical students were the third cohort. Both groups of graduates and clinical students underwent similar medical curriculum following its inception in 2005. A validated selfadministered questionnaire with Cronbach value of 0.8 was emailed or given personally to the contactable graduates with at least 6 months work experience. The questionnaires were given to all final year (Year 6) clinical students at the end of their second clinical posting except for 10 students who had earlier participated in the pilot study. This study is part of a bigger project on the outcome of the Islamic input in medical curriculum and its recommendations for improvements. The questionairre consisted of respondent profile, knowledge, attitude and practice of Islamic input and the personal and professional development. Professionalism was assessed by a total of 11 items on personal and professional characteristics developed based on our expectations of a good Muslim doctor. The respondents were asked to rate their level of agreement or disagreement on the statements that represent the characteristics using a scale of 1 to 4 (1=strongly disagree; 2=disagree; 3 =agree and 4=strongly agree). An even point scale was used to allow respondents to make a stand on the questions. Respondents were requested to answer the questionnaire truthfully and honestly. Data processing and analysis were performed using the SPSS 18.0 for Windows. The mean, median and inter quartile ranges of both personal and professional characteristics were determined and differences between the groups were analysed using Mann-Whitney U test.

\section{RESULTS}

A total of 56 graduates participated in this study with a response rate of $86.2 \%$ ( 25 out of 29$)$ from the first cohort as compared to $72.1 \%$ (31 out of 43 ) from the second cohort. Graduates of the first cohort (mean age of $26.32+0.56$ years) and the second cohort (mean age $2 \overline{5} .42+0.72$ years) have had working experience of $23.76+0.83$ months and 10.64+2.68 months respectively. Table I shows the descriptive statistical results (mean, median, standard deviation, minimum and maximum scores and inter quartile range) for personal and professional characteristics of a Muslim doctor as perceived by graduates according to gender.

Table I. Descriptive statistical results of evaluation of personal and professional characteristics of graduates by gender.

\begin{tabular}{|c|c|c|c|c|}
\hline & \multicolumn{2}{|c|}{$\begin{array}{c}\text { Personal } \\
\text { characteristics }\end{array}$} & \multicolumn{2}{|c|}{$\begin{array}{l}\text { Professional } \\
\text { characeristics }\end{array}$} \\
\hline & Male & Female & Male & Female \\
\hline$N$ & 25 & 31 & 25 & 31 \\
\hline Mean & 22.32 & 21.88 & 18.90 & 18.04 \\
\hline Median & 23.00 & 23.00 & 20.00 & 18.00 \\
\hline SD & 2.02 & 2.54 & 1.45 & 2.11 \\
\hline $\begin{array}{l}\text { Minimum } \\
\text { value }\end{array}$ & 18.00 & 18.00 & 15.00 & 12.00 \\
\hline $\begin{array}{l}\text { Maximum } \\
\text { value }\end{array}$ & 24.00 & 24.00 & 20.00 & 20.00 \\
\hline $\begin{array}{l}\text { Interquartile } \\
\text { ranges (IqR) }\end{array}$ & 3.00 & 5.00 & 2.00 & 3.00 \\
\hline z & & & & 538 \\
\hline $\mathrm{p}$ & & & & 24 \\
\hline
\end{tabular}

Table II shows that the male graduates have a significantly higher median score for the item "Conscious of professional ethics" $(p=0.021)$. There were no other significant differences in the median scores (overall or individual item) for both personal and professional characteristics as perceived by the male and female graduates. Table III shows that there was a significant difference $(p<0.001)$ in the median scores for perceived personal characteristics of Muslim doctors between the graduates and the final year students. Table IV shows the significant differences in the median scores between the 
graduates and the final year students in four out of six items which are "Faith" $(\mathrm{p}=0.002)$, "Attitude towards members of healthcare team" $(p=0.003)$, "Attitude towards colleagues" $(p<0.001)$ and "Self- accountability" $(p=0.003)$. The median scores for items on professional characteristics were however not significantly different between the graduates and the final year students.

Table II. Median scores of items of personal and professional characteristics by gender of graduates.

\begin{tabular}{|c|c|c|c|c|c|c|}
\hline \multirow{2}{*}{$\begin{array}{l}\text { Characteristics } \\
\text { Personal }\end{array}$} & \multicolumn{2}{|c|}{ Male $(n=25)$} & \multicolumn{2}{|c|}{ Female $(n=31)$} & \multirow[t]{2}{*}{$\mathrm{z}$} & \multirow[t]{2}{*}{$\mathrm{p}$} \\
\hline & Median & IqR & Median & IqR & & \\
\hline Faith & 4.00 & 1 & 3.00 & 1 & -1.601 & .109 \\
\hline Responsibility & 4.00 & 1 & 4.00 & 1 & -1.132 & .258 \\
\hline Respect for superiors & 4.00 & 0 & 4.00 & 1 & -.537 & .591 \\
\hline $\begin{array}{l}\text { Attitude towards } \\
\text { healthcare team. }\end{array}$ & 4.00 & 0 & 4.00 & 1 & -.857 & .392 \\
\hline $\begin{array}{l}\text { Attitude towards } \\
\text { colleagues. }\end{array}$ & 4.00 & 0 & 4.00 & 1 & -1.139 & .255 \\
\hline Self-accountability & 4.00 & 0 & 4.00 & 1 & -.020 & .984 \\
\hline \multicolumn{7}{|l|}{ Professional } \\
\hline $\begin{array}{l}\text { Concious of professional } \\
\text { ethics. }\end{array}$ & 4.00 & 0 & 4.00 & 1 & -2.316 & $.021^{*}$ \\
\hline Concious of Islamic rules. & 4.00 & 1 & 4.00 & 1 & -.097 & .922 \\
\hline Excellent performane & 4.00 & 1 & 4.00 & 1 & -1.197 & .231 \\
\hline Strife toward perfection & 4.00 & 0 & 4.00 & 1 & -1.798 & .072 \\
\hline $\begin{array}{l}\text { Communicate the concept } \\
\text { of good clinical practices }\end{array}$ & 4.00 & 1 & 4.00 & 1 & -1.117 & .124 \\
\hline
\end{tabular}

Table III. Descriptive statistical results of evaluation of personal and professional characteristics of graduates by gender.

\begin{tabular}{|c|c|c|c|c|}
\hline & \multicolumn{2}{|c|}{$\begin{array}{c}\text { Personal } \\
\text { characteristics }\end{array}$} & \multicolumn{2}{|c|}{$\begin{array}{l}\text { Professional } \\
\text { characeristics }\end{array}$} \\
\hline & Graduate & $\begin{array}{l}\text { Clinical } \\
\text { Students }\end{array}$ & Graduate & $\begin{array}{l}\text { Clinical } \\
\text { Students }\end{array}$ \\
\hline $\mathrm{N}$ & 56 & 43 & 56 & 43 \\
\hline Mean & 22.13 & 19.95 & 18.52 & 18.00 \\
\hline Median & 23.00 & 2100 & 19.00 & 19.00 \\
\hline SD & 2.26 & 3.56 & 1.81 & 2.72 \\
\hline $\begin{array}{l}\text { Minimum } \\
\text { value }\end{array}$ & 18.00 & 6.00 & 12.00 & 5.00 \\
\hline $\begin{array}{l}\text { Maximum } \\
\text { value }\end{array}$ & 24.00 & 24.00 & 20.00 & 20.00 \\
\hline $\begin{array}{l}\text { Interquartile } \\
\text { ranges (IqR) }\end{array}$ & 3.75 & 5.00 & 3.00 & 3.00 \\
\hline$z$ & & 572 & -.9 & \\
\hline$p$ & & 000 & .3 & \\
\hline
\end{tabular}

\section{DISCUSSION}

Muslim doctors are bound to both professional ethics and Islamic rulings. Thus, items for assessing the percepton of personal and profesional characteristics were developed to represent values that are expected of a Muslim doctor after going through Islamic courses in the medical curriculum. We found that the items that we developed correlated very well with those values of medical professionalism based on the Islamic perspective proposed by Hasan Kasule. ${ }^{1}$ These items are equivalent to the 6 dimensions of good professionalism (altruism, accountability, excellence, duty, honor and integrity, respect for others and honesty) listed by The American Board of Internal Medicine (ABIM). ${ }^{3}$

Our study showed no significant difference between male and female graduates on perception of personal and professional characteristics of a good Muslim doctor except for the item "Conscious of professional ethics" $(p=0.021)$. When we compared the results of the graduates with the final year students, we found that the graduates have significantly greater perception of characteristics of personal development of a good Muslim doctor compared to the final year medical students. On the other hand, there were no significant differences for the professional characteristics between the two 
groups. Thus the study shows that the teaching and learning of professionalism has an impact on graduate perception of medical professionalism. In another local study among medical students in Universiti Sultan Zainal Abidin, Malaysia, they found that there were no significant differences observed between gender $(p=0.536)$ and study-year $(p=0.484){ }^{4}$ With regards to the characteristics of professional development of a Muslim doctor, we expect the graduates to show better perception of professionalism following a greater engagement and opportunity to practise medicine as compared to the final year students.

Professionalism plays a role in decision making, medical errors, relationships with patients, patient satisfaction and health outcomes. ${ }^{5}$ Teaching and evaluating professionalism are important issues in medical education. Various strategies have been used to introduce the culture of professionalism including integration of ethics and humanities. ${ }^{6,7}$ Personal and professional development (PPD) curriculum design should include all aspects of medical practice and interdisciplinary rather than discrete. ${ }^{8}$ In our case, the faculty has taken efforts to promote professionalism by integrating medical ethics and Islamic courses from the very beginning of the medical programme, which includes the domains of knowledge, attitude and skills.

Various methods were used in teaching and learning about PPD. Despite all these, our concern is the internalisation of the professional characteristics of a good Muslim doctor. Other studies have also found a decline in professionalism among the graduates and students. ${ }^{5,9}$ In fact Hojat et al. found a significant decline in empathy during the third year of medical school when empathy is most essential. ${ }^{10}$ Evidence suggesting that hidden curriculum in medical education programmes may actually conflict efforts to teach professionalism. ${ }^{4}$ Some personal factors that could relate to the decline in professionalism include personal distress experienced during training, individual characteristics such as motivation, and personality traits and interpersonal skills. ${ }^{11}$ Thus, the undergraduate teaching of professionalism needs improvement to promote greater impact on the understanding of professionalism.

Nevertheless, efforts to instill the value of PPD will be continued among the students. Interview findings on clinical students (third cohort) and graduates revealed that there should be more practical sessions on medical ethics (unpublished). The faculty has improved the teaching of ethics and professionalism in PPD workshops, integration of Islamic component in all teaching learning activities, participation of students and teachers in community engagements and preparation of a book on guide to PPD for both students and teachers. These efforts are made to inculcate professionalism with integration of a culture of professionalism involving staff, faculty and students. $^{12,13}$ We emphasised the participation of both students and teachers to promote positive role models as well as effective inculcation of professionalism through direct participation. ${ }^{11,14}$ Early assessment and improvement on the method of assessment on medical ethics and Islamic jurisprudence would be considered to detect unprofessional behaviours and attitudes early and allow early correction as suggested by Hasan Kasule. ${ }^{1}$

A qualitative study on the internalisation of the Islamic input involving in-depth interviews of graduates and clinical students are also being carried out to explore their understanding of professionalism. Future study on professionalism among the fourth cohort onwards will also be done to see the effectiveness of the teaching and learning of the improved curriculum.

Effective communication is one of main characteristics of professionalism. Most of our respondents agree with this. In a study done in Hospital Tengku Ampuan Rahimah, Klang Selangor, researchers interviewed medical residents or medical officers in their housemanship years in this study and found out that they generally portrayed higher positive attitudes $(45.7 \pm 6.1)$ as compared to negative attitudes $(22.2 \pm 3.7)$ toward communication skills learning. The respondents whom $61.8 \%$ of them graduated from local universities in Malaysia also believed that learning communication skills would prompt clinicians to respect patients during consultations. ${ }^{15}$

In a study done among medical students in Universiti Kebangsaan Malaysia (UKM) on respondents' opinion about how they learnt professionalism shows that $38 \%$ learnt professionalism through experience, $25 \%$ by role model and $15 \%$ by formal education. As compared to our study, their study showed no significant difference between professionalism and gender. ${ }^{16} \mathrm{~N}$ Sivalingam reported that professionalism in medicine should no longer remain a hidden curriculum but be enhanced and taught in an explicit way in view of the changing trends in medical care and the barriers to professionalism. ${ }^{17}$

\section{Limitation of study}

The study design that we used in this study was cross-sectional study design. The situation may provide different results if another time-frame had been chosen. For future study, we plan to follow up our ex-students and determine the improvement and sustainability of their perception on personal and professional characteristics of a good Muslim doctor.

\section{CONCLUSION}

The teaching of Islamic courses in the medical curriculum aims to enhance the promotion of professionalism in the students and graduates of USIM. Results of this study showed that generally 
the graduates have better perception of personal and professional characteristics of a good Muslim doctor compared to the current students. The final year students showed equal perception of professional characteristics as the graduates. Thus the Islamic courses and the integration of professionalism in the undergraduate training in USIM have an impact on their perception of personal and professional characteristics of a good Muslim doctor. However, further improvement in the undergraduate teaching of professionalism is needed in order to promote greater impact on the understanding and internalization of personal and professional development.

\section{Acknowledgement}

The authors would like to thank Nor Syazana Umar for her contribution in the statistical analysis. This study was supported by USIM Administrator Grant (PPP/PSK/STH/30/ 15612).

\section{REFERENCES}

1. Kasule $\mathrm{OH}$. Medical professionalism and professional organizations. Journal of Taibah University Medical Sciences 2013;8(3):137-41.

2. Jamilah J, Najib AA, Dzulkhairi M, et al. Integration of Islamic Input in Medical Curriculum-Universiti Sains Islam Malaysia (USIM) Experience. The International Medical Journal of Malaysia 2014;13(2):73-77.

3. Medicine AFABol, Medicine A-AFACoP-ASol, European Federation of Internal M. Medical professionalism in the new millennium: a physician charter. Ann Intern Med 2002;136 (3):243-6.

4. Salam A, Yousuf R, Islam MZ, Yesmin F, Helali $A M$, Alattraqchi AG, Rao UM, Haque $M$. Professionalism of future medical professionals in Universiti Sultan Zainal Abidin, Malaysia. Bangladesh Journal of Pharmacology. 2013; 8 (2):124-30.

5. Archer R, Elder W, Hustedde C, et al. The theory of planned behaviour in medical education: a model for integrating professionalism training. Medical education 2008;42(8):771-77.

6. Cottrell S, Samora JB, Shumway J. An Analysis of First-Year Medical Student Comments in a Peer Evaluation of Professionalism. Medical Science Educator 2012;17(1):27-32.

7. Rivera E, Correa R. Implementation of different initiatives to develop a culture of professionalism in the medical school. Puerto Rico health sciences journal 2009;28(2):135-39.

8. Nestel D, Robbe IJ, Jones KV. Personal and professional development in undergraduate health sciences education. J Vet Med Educ 2005;32(2):228-36.

9. Hojat M, Mangione S, Nasca TJ, et al. An empirical study of decline in empathy in medical school. Med Educ 2004;38(9):934-41.
10. Hojat M, Vergare MJ, Maxwell K, et al. The devil is in the third year: a longitudinal study of erosion of empathy in medical school. Acad Med 2009;84(9):1182-91.

11. West CP, Shanafelt TD. The influence of personal and environmental factors on professionalism in medical education. BMC Med Educ 2007;7:29.

12. Passi V, Doug M, Peile JT, et al. Developing medical professionalism in future doctors: a systematic review. International journal of medical education 2010;1:19-29.

13. Haidet $\mathrm{P}$, Stein HF. The role of the studentteacher relationship in the formation of physicians. The hidden curriculum as process. J Gen Intern Med 2006;21 Suppl 1:S16-20.

14. Byszewski A, Hendelman W, McGuinty C, et al. Wanted: role models--medical students' perceptions of professionalism. BMC Med Educ 2012;12:115.

15. Ganasegeran K, Al-Dubai SA. Medical professionalism from a socio-cultural perspective: Evaluating medical residents' communicative attitudes during the medical encounter in Malaysia. Journal of postgraduate medicine. 2014 Jan 1;60(1):12.

16. Salam A, Song CO, Mazlan NF, Lee LS, Abdullah MA, Hassin H. Professionalism of Future Medical Professionals in Universiti Kebangsaan Malaysia (UKM) Medical Centre. Int Med J 2012 ;19(3):224 $-8$.

17. Sivalingam $N$. Teaching and learning of professionalism in medical schools. Ann Acad Med Singapore. 2004;33(6):706-10. 